\title{
DEPENDENCE OF POWER DENSITY OF Ar BOMBARDMENT ON PROPERTIES OF Fe FILMS BY DOUBLE ION BEAM SPUTTERING
}

\author{
Satoshi IWATSUBO ${ }^{1}$, Takakazu TAKAHASHI ${ }^{2}$ and Masahiko NAOE ${ }^{3}$ \\ 1) Toyama Industrial Tech. Cent., 150 Futagami, Takaoka, Toyama 933, JAPAN \\ 2) Toyama Univ., 3190 Guguku, Toyama, Toyama 930, JAPAN \\ 3) Tokyo Inst. Tech., 2-12-2 O-okayama, Meguro-ku, Tokyo 152, JAPAN
}

\section{ABSTRACT}

Fe films have been deposited by double ion beam sputtering with Kaufman type ion source. For the $\mathrm{Ar}$ bombardment ion source, the voltage $\mathrm{V}_{\mathrm{A}}$ was varied in the range of $80-2000 \mathrm{~V}$. The current density $\mathrm{J}_{\mathrm{A}}$ was fixed at 0.49 and $0.049 \mathrm{~A} / \mathrm{m}^{2}$, that is, the power density of $\mathrm{Ar}$ bombardment $P_{A}$, the product of $V_{A}$ and $J_{A}$, was changed in the range of $3.9-980 \mathrm{~W} / \mathrm{m}^{2}$. The $\mathrm{P}_{\mathrm{A}}$ dependence of the magnetic properties of the $\mathrm{Fe}$ films has been investigated in detail.

Fe films with the coercivity $\mathrm{H}_{C}$ below 5 Oe were deposited on the substrates ion-bombarded at $P_{A}$ in the range of 30-70 $\mathrm{W} / \mathrm{m}^{2}$. The saturation magnetization $4 \pi \mathrm{M}_{\mathrm{S}}$ of the films was $21.5 \mathrm{kG}$ at $P_{A}$ of 9.6 and $96 \mathrm{~W} / \mathrm{m}^{2}$. The electric resistivity $\rho$ took the maximum value of $80 \mu \Omega \mathrm{cm}$ at $\mathrm{P}_{\mathrm{A}}$ of $980 \mathrm{~W} / \mathrm{m}^{2}$. This value was 2.7 times as large as that without $\mathrm{Ar}$ bombardment. These results imply that the bombardment by Ar ions with an optimum power density is very useful technique to obtain the Fe films with good magnetic properties and the high electric resistivity for a backlayer of perpendicular recording media.

\section{I . INTRODUCTION}

Fe thin films seem to be hopeful material for large $4 \pi \mathrm{M}_{\mathrm{S}}$ backlayer of $\mathrm{Co}-\mathrm{Cr}$ media for perpendicular magnetic recording. As recording density is high, the unit of recording is small to nano-scale. In the range, the uniformity of composition may be important for the alloy films like NiFe or Co based material. Because the uniformity of backlayer relates to the noise of media and the film growth of perpendicular magnetic layer. Pure Fe films, which are uniform composition have excellent properties for the backlayer. However, it is very difficult to prepare Fe films with a good soft magnetism, since magnetic properties of these are significantly influenced by preparation methods, as listed in Table 1.

\begin{tabular}{lclc}
\hline \multicolumn{4}{c}{ Table 1 Magnetic properties of Fe films } \\
Sputtering method & $4 \pi \mathrm{M}_{\mathrm{s}}(\mathrm{kG})$ & $\mathrm{H}_{\mathrm{C}}(\mathrm{Oe})$ \\
\hline FTS (Facing Target System) & - & $30-60$ & {$[3]$} \\
FTS + bias voltage & $16-21.5$ & $8-20$ & {$[4]$} \\
Sputter beam & - & $10-40$ & {$[5]$} \\
Ion beam & $14-21.5$ & $4-13$ & {$[1][6]$} \\
Double ion beam & $11-21.5$ & $1.5-50$ & {$[2]$} \\
\hline
\end{tabular}

In sputtering, the film surface is always bombarded by the ions from the plasma and the atoms recoiled from the target plane. It is very useful to bombard the films during the film growth in the case of a bias sputtering [4] and an ion-assisted deposition. Therefore, the technique of Ar bombardment can be applicable to control the magnetic properties of the $\mathrm{Fe}$ films.

So far, the energy of the Ar bombardment to the substrate has been only emphasized [1]. However, the relationship between the bombardment effect and the power density has not been mentioned in detail for deposition of Fe films. Taking the density of the energetic particles into consideration, this parameter is very important for the film deposition. Especially, the parameter influences the film temperature.

In this study, Fe films have been deposited by the ion beam sputtering with Ar bombardment as a parameter of the power density $\mathrm{P}_{\mathrm{A}}$. The dependence of the crystallographic and magnetic characteristics of the Fe films on $P_{A}$ and the temperature has been investigated in detail.

\section{II . EXPERIMENT}

A double ion beam sputtering apparatus was used in this study. Both ion sources were Kaufman-type. Specimen films were deposited on water-cooled glass substrates by double ion beam sputtering using an Fe target of $99.9 \%$ in purity. On the other hand, heated specimen films were deposited on glass substrates by ion beam sputtering without Ar bombardment. After the chamber was evacuated to the residual gas pressure lower than $6 \times 10^{-5} \mathrm{~Pa}$, Ar gas of 99.999\% in purity was introduced through the sputtering ion source and used as the sputtering gas. Ar pressure was as high as $3.6 \times 10^{-3} \mathrm{~Pa}$ by setting the gas flow rate at $2 \mathrm{sccm}$. The voltage $\mathrm{V}_{\mathrm{S}}$ for sputtering and the current were kept at $1200 \mathrm{~V}$, and $50 \mathrm{~mA}$, respectively.

For the assisting Ar ion source, the voltage $V_{A}$ for $\mathrm{Ar}$ bombardment was varied from 80 to $2000 \mathrm{~V}$. The current density $J_{A}$ fixed at 0.49 and $0.049 \mathrm{~A} / \mathrm{m}^{2}$ to change $P_{A}$, which was the product of $\mathrm{V}_{\mathrm{A}}$ and $\mathrm{J}_{\mathrm{A}}$. The relationship of $\mathrm{P}_{\mathrm{A}}$ and $\mathrm{V}_{\mathrm{A}}$ as a parameter of $J_{A}$ is shown in figure 1. $P_{A}$ varied from 39 to $980 \mathrm{~W} / \mathrm{m}^{2}$ at $\mathrm{J}_{\mathrm{A}}$ of $0.49 \mathrm{~A} / \mathrm{m}^{2}$ and from 3.9 to $98 \mathrm{~W} / \mathrm{m}^{2}$ at $\mathrm{J}_{\mathrm{A}}$ of $0.049 \mathrm{~A} / \mathrm{m}^{2}$.

The thickness of as-deposited Fe films was in the range of 300-350 $\mathrm{nm}$. The crystal structure was analyzed by X-ray diffractometry. The electrical resistivity $\rho$ was measured by 
means of four-terminal method The saturation magnetization $4 \pi \mathrm{M}_{S}$ and the coercivity $\mathrm{H}_{\mathrm{C}}$ were measured using a vibrating sample magnetometer.

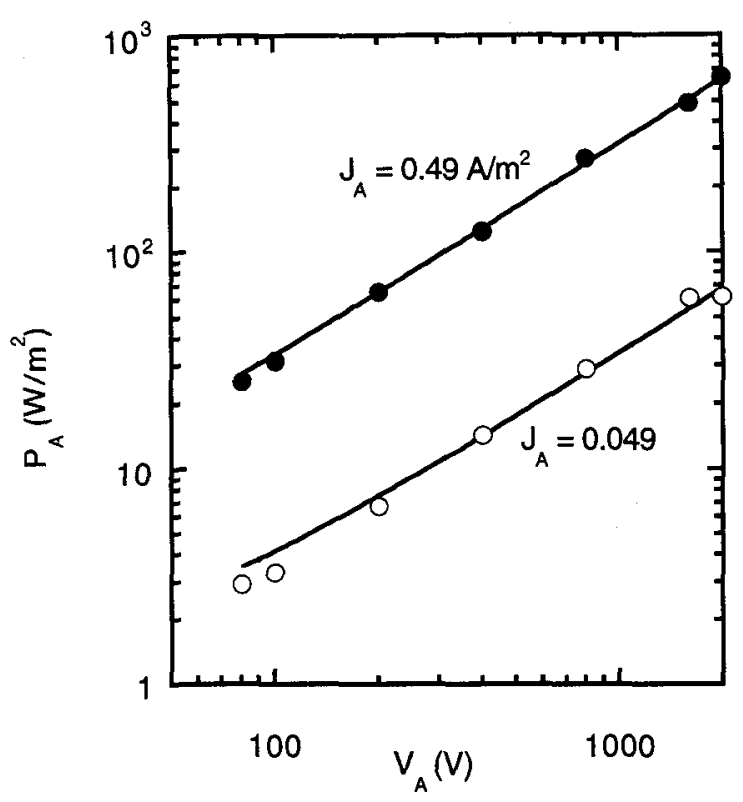

Fig. 1. The relationship between the power density of Ar bombardment $P_{A}$ and the bombardment voltage $V_{A}$ for $J_{A}$ of 0.49 and $0.049 \mathrm{~A} / \mathrm{m}^{2}$.

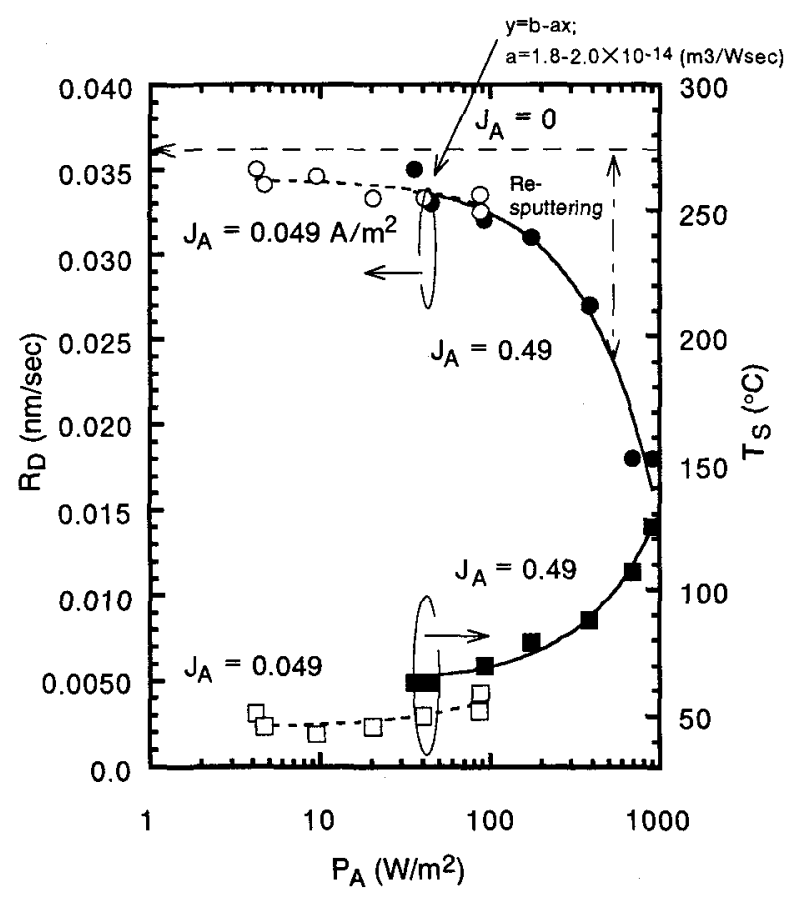

Fig. 2. $P_{A}$ dependence of the deposition rate $R_{D}$ and the substrate holder temperature $T_{S}$ for $\mathrm{J}_{\mathrm{A}}$ of 0.49 and $0.049 \mathrm{~A} / \mathrm{m}^{2}$.

\section{RESULTS AND DISCUSSION}

\section{A. Deposition rate and substrate temperature}

Figure 2 shows the $P_{A}$ dependence of the deposition rate $R_{D}$ and the surface temperature $T_{S}$ of the substrate holder as a parameter of $\mathrm{J}_{\mathrm{A}}$ equal to $0.49,0.049$ and $0 \mathrm{~A} / \mathrm{m}^{2}$. $\mathrm{J}_{\mathrm{A}}$ of 0 means that the film was deposited without Ar bombardment and $R_{D}$ was $0.036 \mathrm{~nm} / \mathrm{sec}$. For $\mathrm{J}_{\mathrm{A}}$ of 0.49 and $0.049 \mathrm{~A} / \mathrm{m}^{2}$, $R_{D}$ decreased in proportion to $P_{A}$. The gradients of the line for $\mathrm{J}_{\mathrm{A}}$ of 0.49 and $0.049 \mathrm{~A} / \mathrm{m}^{2}$ were $-2.0 \times 10^{-14}$ and $-1.8 \times$ $10^{-14} \mathrm{~m}^{3} /$ Wsec, respectively. These values were almost same. The sputtering yield was in proportion to the sputtering voltage in the range from 100 to $10000 \mathrm{~V}$. In this experiment, $\mathrm{P}_{\mathrm{A}}$ was product of $\mathrm{V}_{\mathrm{S}}$ and $\mathrm{J}_{\mathrm{A}}$. Therefore, the difference from $R_{D}$ for $J_{A}$ of 0 shows the rate of re-sputtering from the film by the bombardment.

On the other hand, $T_{S}$ also increased with an increase of $\mathrm{P}_{\mathrm{A}}$. For $\mathrm{P}_{\mathrm{A}}$ below $39 \mathrm{~W} / \mathrm{m}^{2}$ at $\mathrm{J}_{\mathrm{A}}$ of $0.049 \mathrm{~A} / \mathrm{m}^{2}$, the variation of $T_{S}$ was very small. $T_{S}$ was about $45^{\circ} \mathrm{C}$. For $P_{A}$ over $39 \mathrm{~W} / \mathrm{m}^{2}$ at $\mathrm{J}_{\mathrm{A}}$ of $0.49 \mathrm{~A} / \mathrm{m}^{2}, \mathrm{~T}_{\mathrm{S}}$ increased in proportion to $\mathrm{P}_{\mathrm{A}}$. The maximum value of $\mathrm{T}_{\mathrm{S}}$ was $120^{\circ} \mathrm{C}$, even though the substrate holder was cooled by water. The difference between $\mathrm{J}_{\mathrm{A}}$ of 0.49 and $0.049 \mathrm{~A} / \mathrm{m}^{2}$ at $\mathrm{P}_{\mathrm{A}}$ in the range from 39 to $98 \mathrm{~W} / \mathrm{m}^{2}$ was caused by the heat from the filaments of the assisting ion source. Therefore, the increase of $T_{S}$ was mainly due to the bombardment effect and the thermal emission from the ion sources. The surface temperature of the deposited films may be higher than $\mathrm{T}_{\mathrm{S}}$ as measured at the substrate holder.

\section{B. Crystallographic characteristics}

Xray diffraction diagrams of the as-deposited Fe films as a parameter of $\mathrm{P}_{\mathrm{A}}$ were measured. The crystallographic characteristics changed remarkably with $\mathrm{P}_{\mathrm{A}}$. The $\mathrm{X}$-ray diffraction peaks corresponding to the (110) and (200) planes of $\alpha-\mathrm{Fe}$ crystallites were observed.

Figure 3 shows the $\mathrm{P}_{\mathrm{A}}$ dependence of the lattice constant " $a$ " and the ratio in $(200) /(110)$ integral peak intensity $\mathbf{R}_{(200) /(10)}$ in X-ray diffraction diagrams of the as-deposited $\mathrm{Fe}$ films for $J_{A}$ of 0.49 and $0.049 \mathrm{~A} / \mathrm{m}^{2}$. These values were larger than that of the bulk pure Fe $2.8664 \AA$. "a" was 2.886 $\AA$ for $\mathrm{J}_{\mathrm{A}}$ of 0 . For $\mathrm{J}_{\mathrm{A}}$ of $0.049 \mathrm{~A} / \mathrm{m}^{2}$, "a" increased in proportion to $\mathrm{P}_{\mathrm{A}}$. However, for $\mathrm{J}_{\mathrm{A}}$ of $0.49 \mathrm{~A} / \mathrm{m}^{2}$, " $\mathrm{a}$ " decreased with an increase of $P_{A}$. The decrease of " $a$ " for $J_{A}$ of $0.49 \mathrm{~A} / \mathrm{m}^{2}$ may be caused by the elevation of the film temperature as shown in Fig. 3.

On the other hand, $\mathrm{R}_{(200) /(110)}$ with Ar bombardment was smaller than that without Ar bombardment. $R_{(200) /(10)}$ for $J_{A}$ of $0.49 \mathrm{~A} / \mathrm{m}^{2}$ was smaller than that for $\mathrm{J}_{\mathrm{A}}$ of $0.049 \mathrm{~A} / \mathrm{m}^{2}$. $R_{(200) /(110)}$ took the minimum value at $P_{A}$ of $96 \mathrm{~W} / \mathrm{m}^{2}$ for $J_{A}$ of $0.49 \mathrm{~A} / \mathrm{m}^{2}$ and at $\mathrm{P}_{\mathrm{A}}$ of $20 \mathrm{~W} / \mathrm{m}^{2}$ for $\mathrm{J}_{\mathrm{A}}$ of $0.049 \mathrm{~A} / \mathrm{m}^{2}$. 
In order to investigate the dependence on the substrate temperature, the substrate holder was heated in the range of 50 to $400^{\circ} \mathrm{C}$ using the filament without water-cooling. Figure 4 shows the dependence of "a" and $R_{(200) /(110)}$ on $T_{S}$ by the heater. "a" decreased with an increase of $\mathrm{T}_{\mathrm{S}}$. "a" over $300^{\circ} \mathrm{C}$ was smaller than that of the bulk pure Fe $2.8664 \AA$. $R_{(200) /(110)}$ took the minimum value at $T_{S}$ of $100^{\circ} \mathrm{C}$. The variations of " $a$ " and $R_{(200) /(110)}$ corresponded to that of $\mathrm{P}_{A}$ for $\mathrm{J}_{\mathrm{A}}$ of $0.49 \mathrm{~A} / \mathrm{m}^{2}$. Therefore, Ar bombardment with the elevation of $T_{S}$ by the high $P_{A}$ appeared the only effects of the elevation of $T_{S}$ by the heater. The effects of pure $A r$ bombardment based on the collisions between the atoms of the films and Ar ions may be obtained for $\mathrm{J}_{\mathrm{A}}$ of $0.049 \mathrm{~A} / \mathrm{m}^{2}$.

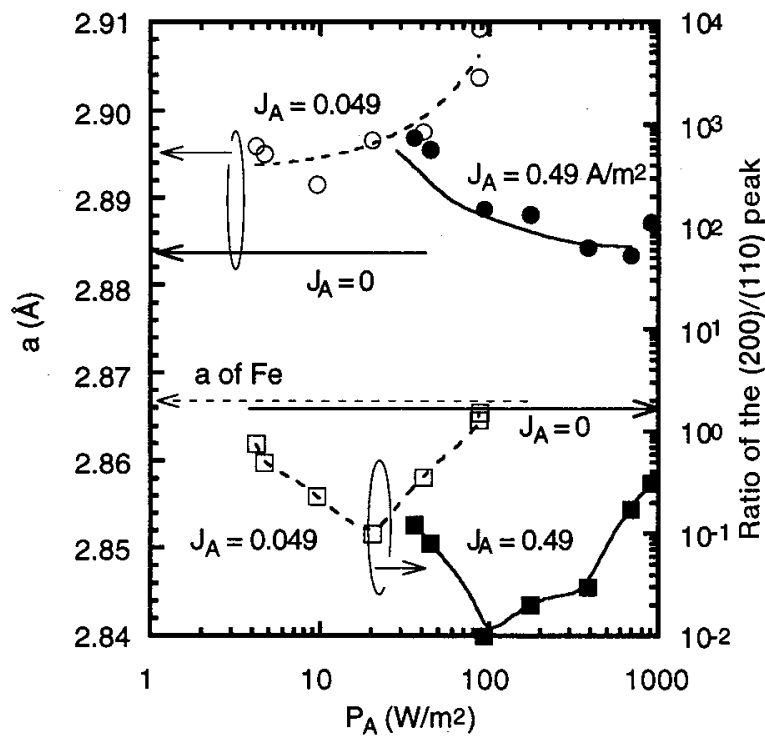

Fig. 3. $P_{A}$ dependence of the lattice constant a and the ratio of $(200) /(110)$ intergral peak intensity $R_{(200) /(110)}$.

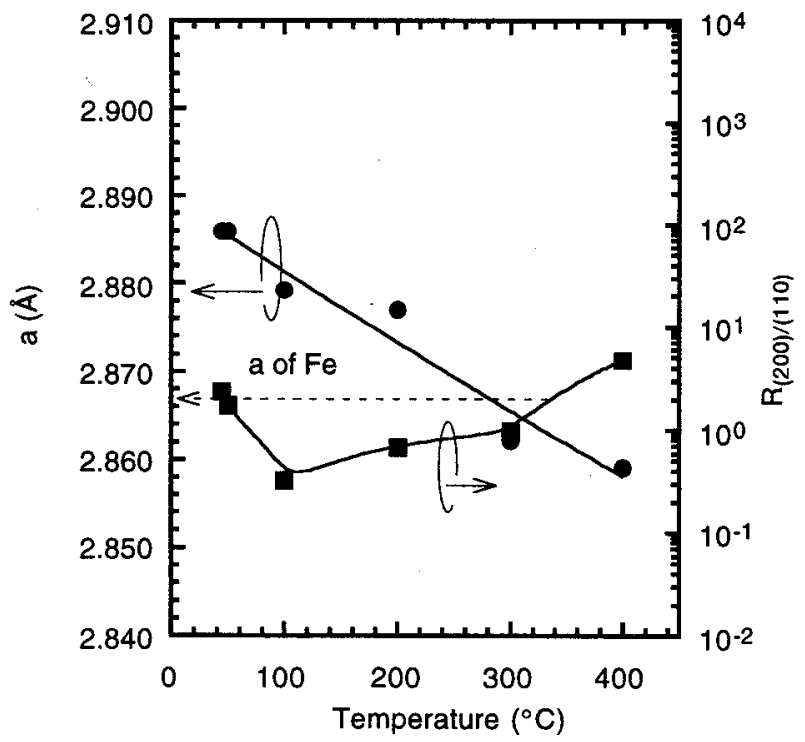

Fig. 4. Dependence of $a$ and $R_{(200) /(110)}$ on $\mathrm{T}_{S}$ by the heater .

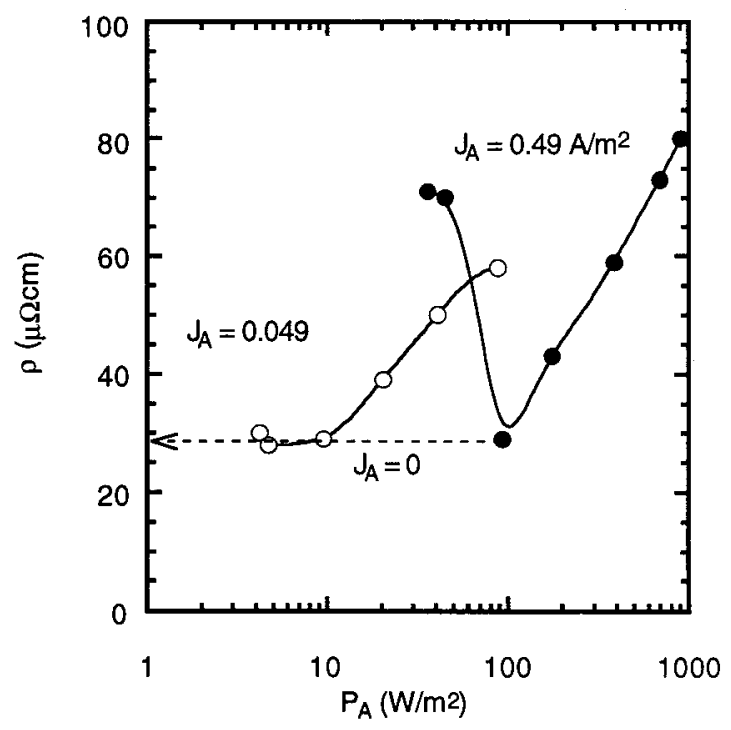

Fig. 5. $P_{A}$ dependence of the electric resistivity $\rho$.

\section{Electric resistivity}

The electric resistivity of backlayer was very important parameter to the performance for high density recording of perpendicular media. When the data transfer rate was over $200 \mathrm{MBit} / \mathrm{sec}$, the eddy current loss of magnetic field was necessarily occurred. Namely, the backlayer of perpendicular media must have a higher electric resistivity for achieving the high density recording. Figure 6 shows the $P_{A}$ dependence of the electric resistivity $\rho$ of the films. $\rho$ was 30 $\mu \Omega \mathrm{cm}$ for $J_{\mathrm{A}}$ of 0 . $\rho$ was almost constant at $P_{\mathrm{A}}$ below 9.6 $\mathrm{W} / \mathrm{m}^{2}$. At $\mathrm{P}_{\mathrm{A}}$ over $9.6 \mathrm{~W} / \mathrm{m}^{2}, \rho$ was higher than that of $J_{A}$ of 0 . At $P_{A}$ of $98 \mathrm{~W} / \mathrm{m}^{2}$, which was the product of $\mathrm{V}_{\mathrm{A}}$ of $200 \mathrm{~V}$ and $J_{A}$ of $0.49 \mathrm{~A} / \mathrm{m}^{2}, \rho$ decreased abruptly. AtP $P_{A}$ in the range of $\mathrm{V}_{\mathrm{A}}$ higher than $200 \mathrm{~V}$ for both $\mathrm{J}_{\mathrm{A}}$ of 0.49 and $0.049 \mathrm{~A}^{2} \mathrm{~m}^{2}$, $\rho$ increased with increasing $V_{A}$. The variation of $\rho$ for $J_{A}$ of $0.49 \mathrm{~A} / \mathrm{m}^{2}$ was larger than that for $\mathrm{J}_{\mathrm{A}}$ of $0.049 \mathrm{~A} / \mathrm{m}^{2}$. $\rho$ took the maximum value of $80 \mu \Omega \mathrm{cm}$ at $\mathrm{P}_{\mathrm{A}}$ of $980 \mathrm{~W} / \mathrm{m}^{2}$. This value was about 2.7 times as high as that of $J_{A}$ of 0 . The electric resistivity of the films depended on the bombardment power density rather than bombardment voltage.

\section{Magnetic Properties}

Figure 6 shows the $P_{A}$ dependence of $4 \pi M_{S}$ and $H_{C}$ of the Fe films. At $P_{A}$ of 9.6 and $96 \mathrm{~W} / \mathrm{m}^{2}$, which was the product of $\mathrm{V}_{\mathrm{A}}$ of $200 \mathrm{~V}$ and both $\mathrm{J}_{\mathrm{A}}, 4 \pi \mathrm{M}_{\mathrm{S}}$ took the maximum value of $21.5 \mathrm{kG}$. The variation of $4 \pi \mathrm{M}_{\mathrm{S}}$ for $\mathrm{J}_{\mathrm{A}}$ of $0.049 \mathrm{~A} / \mathrm{m}^{2}$ was smaller than that for $\mathrm{J}_{\mathrm{A}}$ of $0.49 \mathrm{~A} / \mathrm{m}^{2}$.

On the other hand, $\mathrm{H}_{\mathrm{C}}$ was also almost 5 Oe at $\mathrm{P}_{\mathrm{A}}$ below $9.6 \mathrm{~W} / \mathrm{m}^{2}$. At $\mathrm{P}_{\mathrm{A}}$ in the range of 9.6 to $200 \mathrm{~W} / \mathrm{m}^{2}, \mathrm{H}_{\mathrm{C}}$ was below $5 \mathrm{Oe}$, except the value of $\mathrm{V}_{\mathrm{A}}$ of $80 \mathrm{~V}$ for $\mathrm{J}_{\mathrm{A}}$ of 0.49 
mA. At $P_{A}$ higher than $380 \mathrm{~W} / \mathrm{m}^{2}, \mathrm{H}_{\mathrm{C}}$ increased drastically with increasing $\mathrm{P}_{\mathrm{A}} . \mathrm{H}_{C}$ took the minimum value of $2 \mathrm{Oe}$ at $\mathrm{P}_{\mathrm{A}}$ of $39 \mathrm{~W} / \mathrm{m}^{2}$, which was the product of $\mathrm{V}_{\mathrm{A}}$ of $800 \mathrm{~V}$ and $\mathrm{J}_{\mathrm{A}}$ of $0.049 \mathrm{~mA}$. These results show the power density of $\mathrm{Ar}$ bombardment in the range of 38 to $96 \mathrm{~W} / \mathrm{m}^{2}$ was available to obtain the good soft magnetism of the Fe films.

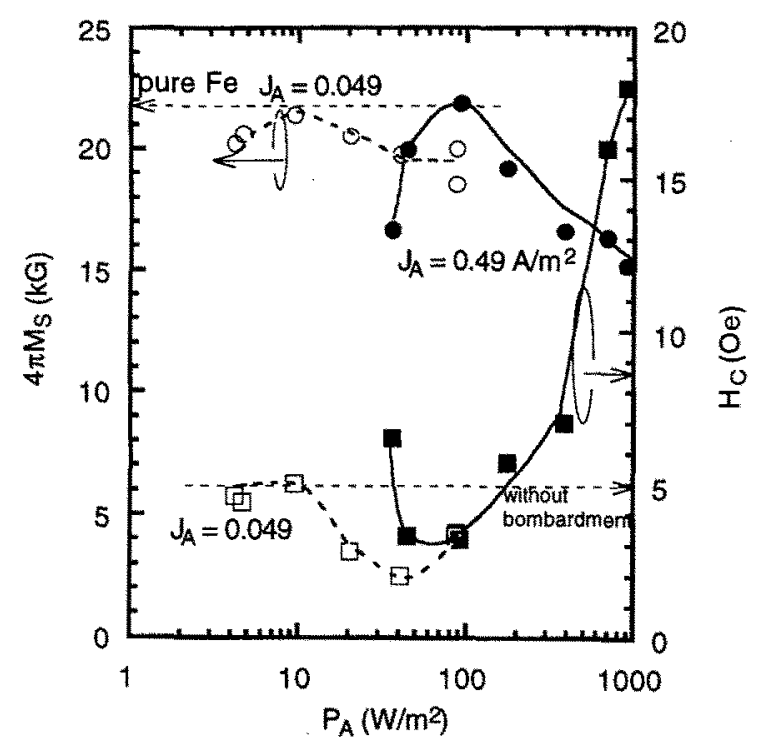

Fig. 6. $P_{A}$ dependence of the saturation magnetization $4 \pi \mathrm{M}_{S}$ and the coercivity $\mathrm{H}_{C}$.

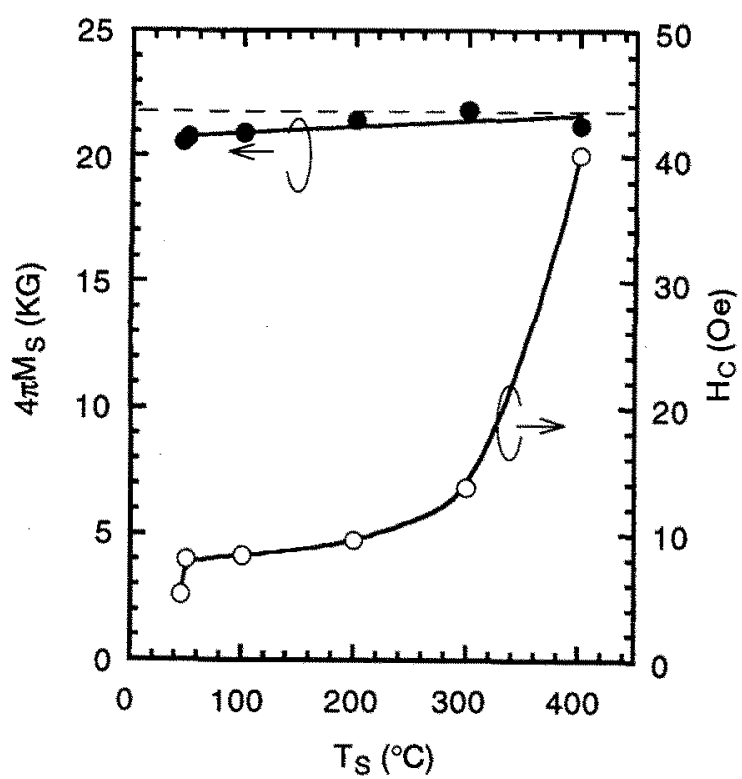

Fig. 7. Dependence of $4 \pi \mathrm{M}_{S}$ and $H_{C}$ on $T_{S}$ by the heater.
Since the decrease of $4 \pi \mathrm{M}_{S}$ corresponded to the increase of $\rho$, the variation of both $4 \pi M_{S}$ and $\rho$ may be caused by Ar included in the $\mathrm{Fe}$ films and the formation of the mixing layer between deposited film and substrate in the range of the high energy bombardment.

Figure 7 shows the dependence of $4 \pi \mathrm{M}_{\mathrm{S}}$ and $\mathrm{H}_{\mathrm{C}}$ on $\mathrm{T}_{\mathrm{S}}$ by the heater. $4 \pi \mathrm{M}_{\mathrm{S}}$ was an almost constant value of $21 \mathrm{kG}$. At $\mathrm{T}_{\mathrm{S}}$ below $300^{\circ} \mathrm{C}, \mathrm{H}_{\mathrm{C}}$ gradually increased with increasing $\mathrm{T}_{\mathrm{S}}$. At $\mathrm{T}_{\mathrm{S}}$ of $300^{\circ} \mathrm{C}, \mathrm{H}_{\mathrm{C}}$ of the film was 40 Oe. The elevation of the film temperature had the effect of the increase of $\mathrm{H}_{C}$. Therefore, the high density Ar bombardment led the increase of $\mathrm{H}_{\mathrm{C}}$. The Ar bombardment without the strong elevation of temperature was effective to decrease of $\mathrm{H}_{\mathrm{C}}$.

\section{CONCLUSION}

Varying the power density of the Ar bombardment technique, the magnetic properties and electric resistivity of the Fe films were controlled. The Fe films with good soft magnetism can be deposited at the optimum power density in the range of 38 to $96 \mathrm{~W} / \mathrm{m}^{2}$. Moreover, it was necessary for the films with high resistivity to deposit at high energy bombardment. At $P_{A}$ of $38 \mathrm{~W} / \mathrm{m}^{2}$, which is $V_{A}$ of $800 \mathrm{~V}$ and $J_{\mathrm{A}}$ of $0.049 \mathrm{~A} / \mathrm{m}^{2}, 4 \pi \mathrm{M}_{\mathrm{S}}$ was $21.5 \mathrm{kG}$ and $\rho$ was $50 \mu \Omega \mathrm{cm}$. These values were twice as high as one of $\mathrm{Ni}_{80} \mathrm{Fe}_{20}$ alloy. Therefore, the $\mathrm{Fe}$ films deposited with high energy bombardment can be expected for the excellent backlayer for the perpendicular recording media.

\section{REFERENCES}

[1] M. Nagakubo, A. Kadokura and M. Naoe, "Prepaeration and Gas addition of Soft Magnetic Pure Iron Thin Film by Dual Ion Beam Sputtering", Mat. Res. Soc. Vol. 80, pp. 415 (1987)

[2] M. Naoe, Y. Yamaga, N. Terada, "Deposition of Rust Proof Iron Thin Films with Soft Magnetic Properties by Dual Ion Beam Sputtering", IEEE Trans. Magn., MAG-21, 1900 (1985)

[3] Y. Hoshi, N. Naoe, S. Yamanaka, "Uniaxial Magnetic Anisotropy of Iron Thin Films Deposited by Targets Facing Type of Sputtering", IECE, J65-C(11), 921 (1982) [in Japanese]

[4] A, Fukizawa, N. Naoe, "Sputtered Pure Iron Film for Soft Magnetic Layer in Perpendicular Recording Media", IEEE Trans. Magn., Vol. 24, No. 6, 3078 (1988)

[5] S. Okamoto, Y. Shimada, M. Suzuki, "Crystal Structure and Magnetic Properties of Fe Films Produced by the Sputter Beam Method", : J. Mag. Soc. Japan Vol. 17, No. 1, 43 (1993) [in Japanese]

[6] N. Ishiwata, C. Wakabayashi, T. Matsumoto, "Zero Magnetrostriction Iron Films", IEEE Trans. Magn., Vol. 24 , No. 6, 3078 (1988) 